\title{
Breast Cancer Monitoring and Tracking System using Soft Computing and Expert System for Healthcare Support
}

\author{
Atiya Masood Rana ${ }^{1}$, Somaya Abdullah Al Gamdi ${ }^{2}$, \\ Roa'a Abdulraheem bukhari ${ }^{3}$, Maryam Tami Al-Osaimi ${ }^{4}$ \\ ${ }^{1}$ (Management Science, Yanbu University College, Pakistan) \\ 2,3,4 (Management Science, Yanbu University College, Saudi Arabia)
}

\begin{abstract}
The decision process for selecting the best-suited follow-up treatment for suspected breast cancer cases are strongly dependent upon the correct diagnosis and assessment of the breast cancer risk. This study will develop an expert system with soft computing methods by using Fuzzy logic and Bayesian network. This system has five input variables and one output variable (risk status). The output variable is a value from 1 to 4; representing low risk status, intermediate risk status, high risk status and very high risk. This study will help to diagnosis and monitor breast cancer at home.
\end{abstract}

Keywords: Breast cancer diagnosis, fuzzy intelligent technique, Soft Computing, Expert system, Probabilistic reasoning, Bayesian Network.

\section{Introduction}

Cancer is a leading life threatening disease that cause cancer cell or lumps in a body to change and grow out of control. One of the most common cancer among women is breast cancer and it is one of the leading cause of cancer related death in women. According to research one in ten ratio of all new cancers diagnosed worldwide each year is the cancer of the female breast cancer and it is the most common cancer in women in both developing and developed countries [1]. In 2011,39,520 death cases due to the breast cancer were recorded in USA [2]. This research is shown in Table1.

\begin{tabular}{|c|c|c|c|}
\hline Age & In Situ Cases & Invasive Cases & Deaths \\
\hline Under 40 & 1,780 & 11.330 & 1,160 \\
\hline Under 50 & 14,240 & 50,430 & 5,240 \\
\hline $50-64$ & 23,360 & 81,970 & 11,620 \\
\hline $65+$ & 20,050 & 98,080 & 22,660 \\
\hline All ages & 57,650 & 230,480 & 39,520 \\
\hline \multicolumn{4}{|c|}{$\begin{array}{l}\text {-Rounded to the nearest } 10 . \\
\text { Source: Total estimated cases are based on } 1995-2007 \text { incidence rates from } \\
46 \text { states as reported by the North American Association for Central Cancer } \\
\text { Registries. Total estimated deaths are based on data from US Mortality Data, } \\
1969-2007 \text {, National Center for Health Statistics, Centers for Disease Control } \\
\text { and Prevention. } \\
\text { American Cancer Society, Surveillance Research, } 2011\end{array}$} \\
\hline
\end{tabular}

Table1:Estimated New Female Breast Cancer Cases and Deaths by Age,US,2011

In Saudi Arabia, the number of new cases of all cancer is 2741 including about $19.9 \%$ of breast cancer in women and it is usually occurs in women at the age of 52.This ratio can be reduced, if cancer diagnosis is done in early stage. The National Cancer Institute estimates that approximately 2.6 million US women with a history of breast cancer were alive in January 2008, more than half of whom were diagnosed less than 10 years earlier .Currently, digital mammography is one of the most promising cancer control strategies in earliest stages but not all the hospitals have digital mammography and it is one of the expensive techniques for cancer control. In recent years Intelligent system that uses different Artificial Intelligence methods such as an expert system and soft computing has been used in medical field for diagnosing and treatment of many diseases. This can be true for breast cancer management. Therefore we planned to use expert system with soft computing for diagnosing the risk status of breast cancer.

\section{Analytical Study}

According to the American cancer society estimates that breast cancer incidence and death rates generally increase with age [2] as shown in Figure- 1. 95\% of breast cancer occurred in women 40 years of age and older. 


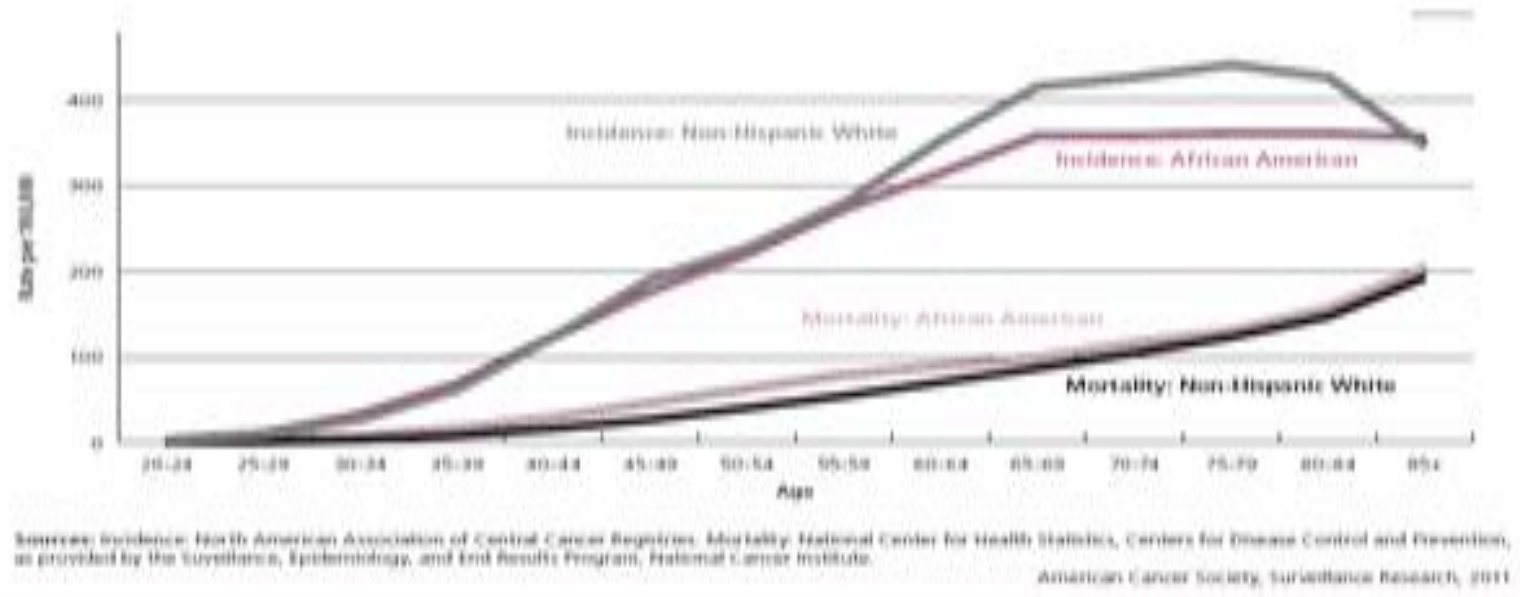

Fig-1:Age-Specific Female Breast Cancer incidence(2004-2008) and Mortality (2003-2007)Rates

Race is also an important factor of breast cancer and according to the American cancer society breast cancer incidence rates are higher in non-Hispanic white women compared to African -American women for most age groups that shows in Figure 1. However, African- American women have a higher incidence rate before 40 years of age [2]. Breast cancer is more common in African- American women. Asian, Hispanic, and Native-American women have a lower risk of developing and dying from breast cancer [3].

Breast Cancer risk is higher among whose close blood relationship, such as sister, mother or daughter has this risk. According to the research those having a relative with first degree cancer diagnosis has threat of a double risk and having 2 first-degree relatives increases her risk about 3-fold [3].

Age at first birth is one of the main reason of breast cancer. Women who have had no children or who had their first child after age 30 have a slightly higher breast cancer risk. Also age at first menarche is an important factor of breast cancer and according to the research women who have had more menstrual cycles because they started menstruating early (before age 12) and/or went through menopause later (after age 55) have a slightly higher risk of breast cancer. Late menopause increases the risk of breast cancer. Women who have undergone the menopause have a lower risk of breast cancer than pre-menopausal women of the same age and childbearing pattern [3].

Although breast cancer has many causes but in this research we consider only five factors . individual risk factors and certainty factors is shown in Table2.

\begin{tabular}{|l|l|}
\hline Risk Factors & $\begin{array}{l}\text { Breast cancer Certainty } \\
\text { Factor }\end{array}$ \\
\hline \multicolumn{2}{|c|}{ Age } \\
\hline$\leq 29$ & $0.06 \%$ \\
\hline $30-39$ & $0.4 \%$ \\
\hline $40-59$ & $2.3 \%$ \\
\hline $60-70$ & $3.8 \%$ \\
\hline \multicolumn{2}{|c|}{ Race } \\
\hline Mixed/Others & $3 \%$ \\
\hline Black & $7 \%$ \\
\hline Hispanic & $11 \%$ \\
\hline White & $72 \%$ \\
\hline First degree relative with breast cancer \\
\hline 0 & $5 \%$ \\
\hline 1 & $20 \%$ \\
\hline$>=2$ & $40 \%$ \\
\hline \multicolumn{2}{|c|}{ Age at menarche } \\
\hline $12-13$ & $12 \%$ \\
\hline$<12$ or $\geq 15$ & $44 \%$ \\
\hline \multicolumn{2}{|c|}{ Age at first birth } \\
\hline$<20$ & $17 \%$ \\
\hline $20-29$ & $31 \%$ \\
\hline$\geq 30$ or None & $49 \%$ \\
\hline
\end{tabular}

Table2: Individual risk factors and it certainty factors 


\section{Discussion With Proposed system}

There is a strong need of monitoring and tracking that can show the severity and certainty of breast cancer . This proposed system is an Intelligent system that is based upon probabilistic reasoning and fuzzy logic . Fuzzy logic and probabilistic reasoning are techniques of soft computing and these techniques are used in inference engine of Expert system.

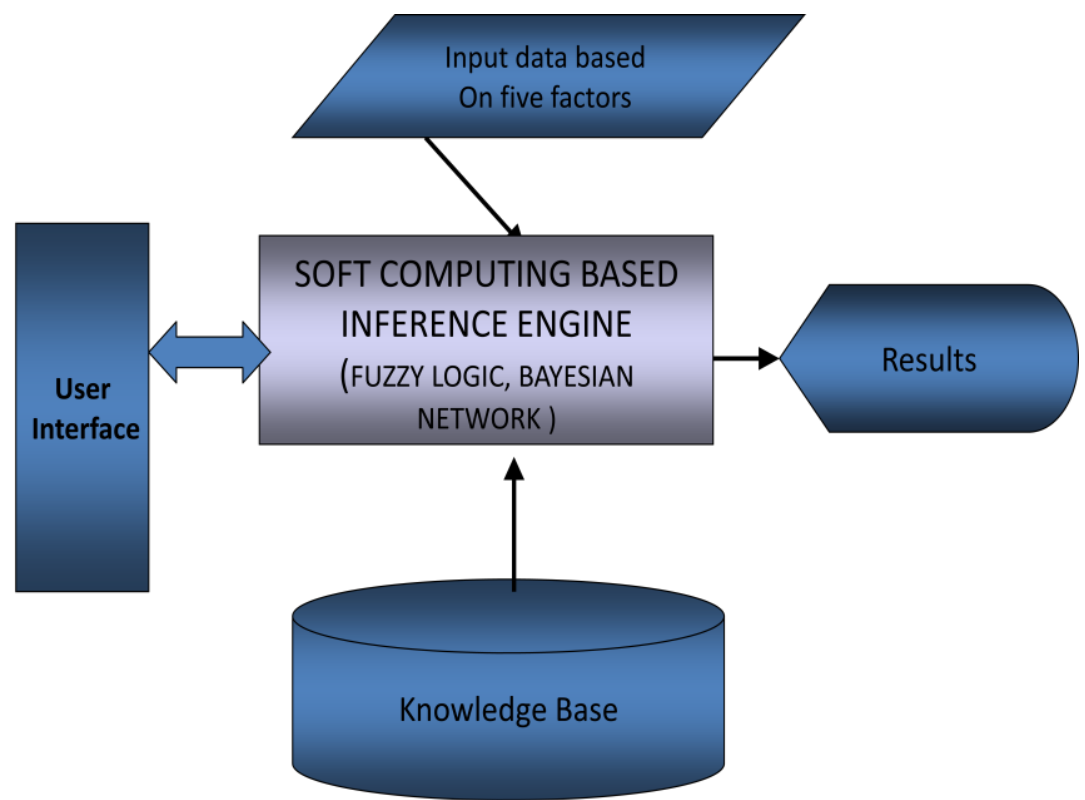

Fig- 2: Architecture of Monitoring Breast Cancer

\subsection{Soft Computing}

One of the most important feature of this research is diagnoses. The soft computing approach with foundation of Fuzzy Logic, Bayesian Network can be helpful for diagnosis of breast cancer. Inference engine will use five inputs and apply Bayesian and fuzzy algorithm in order to extract knowledge as output, so that in future it will help physicians and patient to diagnose breast cancer . Furthermore, this system records patient's age ,race, gender that is a future research requirement to determine consequences based on age-group , gendergroup and Race -group. Figure-2 expresses the methodological architecture of breast cancer. The Soft Computing based inference engine develops the inference using algorithms of Fuzzy Logic and Bayesian network taking the data input from user. The User Interface provides access and interaction between system and user. User could be doctor, paramedic staff, or patient itself [4].

\subsection{Fuzzy Logic}

Fuzzy-type uncertainty measure, expressed in verbal form, is transferred to the same types of numerical representation; the meaning is, on the one hand, a philosophical explanation, beyond the computer representation process; on the other hand, it is a simple look-up table representation attaching the 0 to $l$ values to different verbal set membership measures [5].Figure-3 shows the structure of fuzzy logic system.

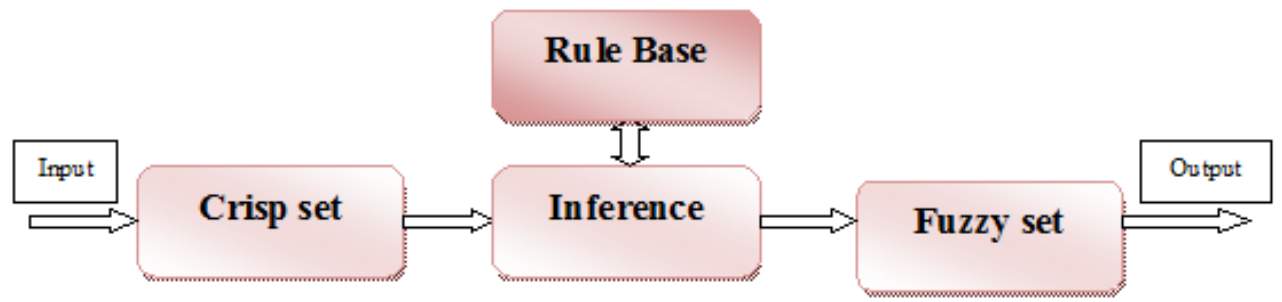

Fig 3: Architecture of Fuzzy Logic System

Fuzzy logic system has three main operations. First, fuzzification that transformed crisp sets to fuzzy sets, second Rule based inference. The fuzzy output needs to be interfaced to the crisp domain by the defuzzifier by using suitable membership functions and it is called defuzzification. In this research we also use these operation and it shows in Table 4-9. 
Breast Cancer Monitoring and Tracking System using Soft Computing and Expert System....

\subsection{Bayesian Network}

A classic probabilistic-related model is the Bayesian; it concerns certain classes of events within the realm of the total observation. The Bayesian model supposes well-defined classes, reliable sampling methods, and a relevant amount of data for each class. The condition of independence belongs also to the model hypothesis. The Bayesian model establishes the well-known relation between a priori and a posteriori estimations, i.e., probability of an effect, if we know the probability of a certain cause, and vice versa, the probability of a cause based on the known probability of an effect[5].In our research we determine conditional probability of breast cancer, where age, race, first degree relative with breast cancer, Age at menarche and age at first birth are known probabilities.

\section{Design of the system}

As mentioned above that this research focused on five factors and It shows in Table 3.

\begin{tabular}{|l|l|l|l|l|}
\hline Age & Less than or equal 29 & Between 30 And 39 & Between 40 And 59 & $\begin{array}{l}\text { Between 60 And } \\
70\end{array}$ \\
\hline Race & Mixed & Black & Hispanic & White \\
\hline Family History & 0 & one or more & & \\
\hline $\begin{array}{l}\text { Age at } \\
\text { menarche }\end{array}$ & $\begin{array}{l}\text { Between 12 and 13 years } \\
\text { old }\end{array}$ & Less than 12 years old & $\begin{array}{l}\text { More than or equal 15 years } \\
\text { old }\end{array}$ & \\
\hline $\begin{array}{l}\text { Age at first } \\
\text { birth }\end{array}$ & Less than 20 years old & $\begin{array}{l}\text { between 20 and 29 years } \\
\text { old }\end{array}$ & $\begin{array}{l}\text { More than or equal 30 years } \\
\text { old }\end{array}$ & None \\
\hline
\end{tabular}

Table3: Individual risk factors and it Ranges

In our research first we describe input variables with membership function and certainty factors . In second step, we introduce the output variable with its membership functions and it is shows in figure 4

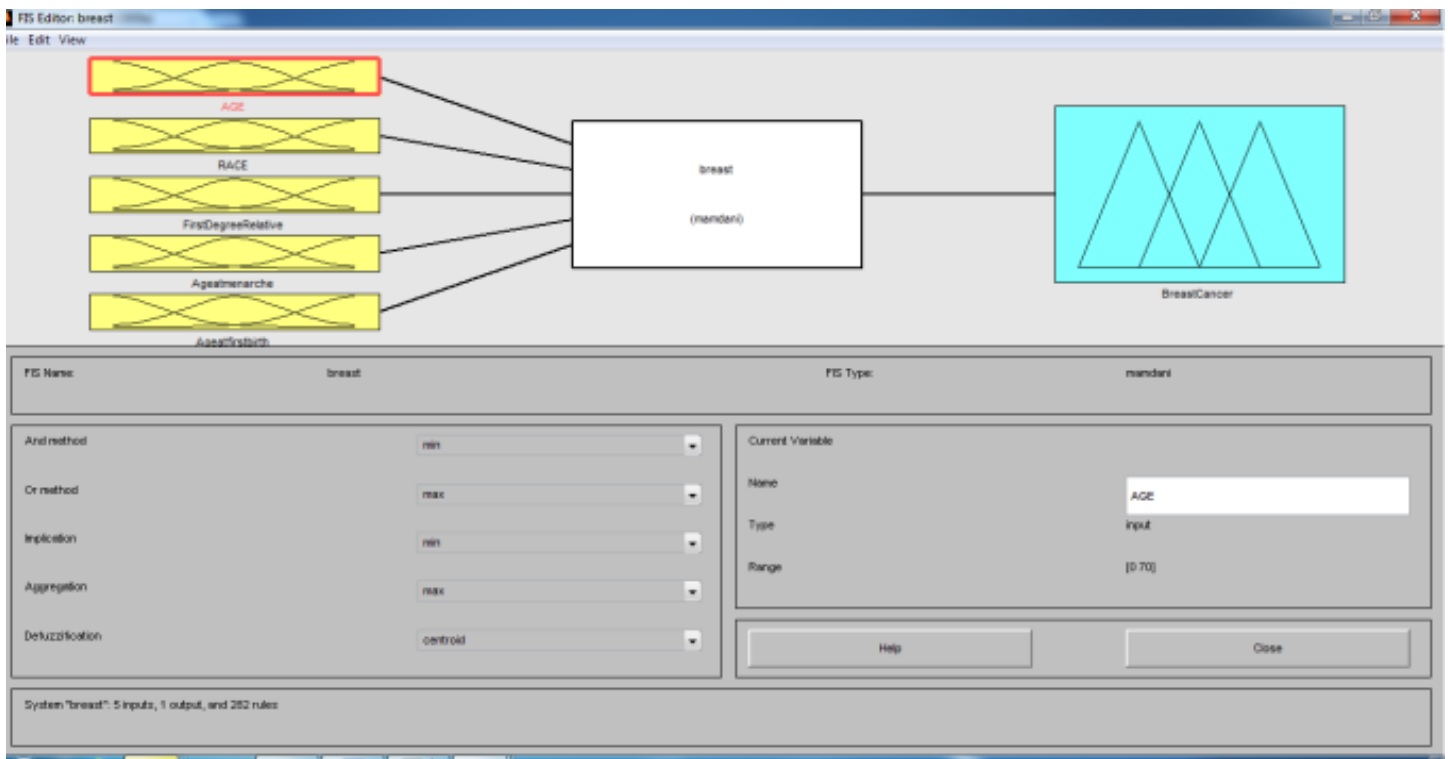

Fig- 4: Input and Output variables

Age input variable has four fuzzy sets "Low, Medium, High and Very High" with individual probabilities.

\begin{tabular}{|c|c|c|}
\hline Risk Factors & Fuzzy Set & Breast cancer Risk \\
\hline \multicolumn{3}{|c|}{ Age } \\
\hline$\leq 29$ & Low & $0.06 \%$ \\
\hline $30-39$ & Medium & $0.4 \%$ \\
\hline $40-59$ & High & $2.3 \%$ \\
\hline $60-70$ & Very High & $3.8 \%$ \\
\hline
\end{tabular}

Table 4:Fuzzy Sets Of Age 
Breast Cancer Monitoring and Tracking System using Soft Computing and Expert System....

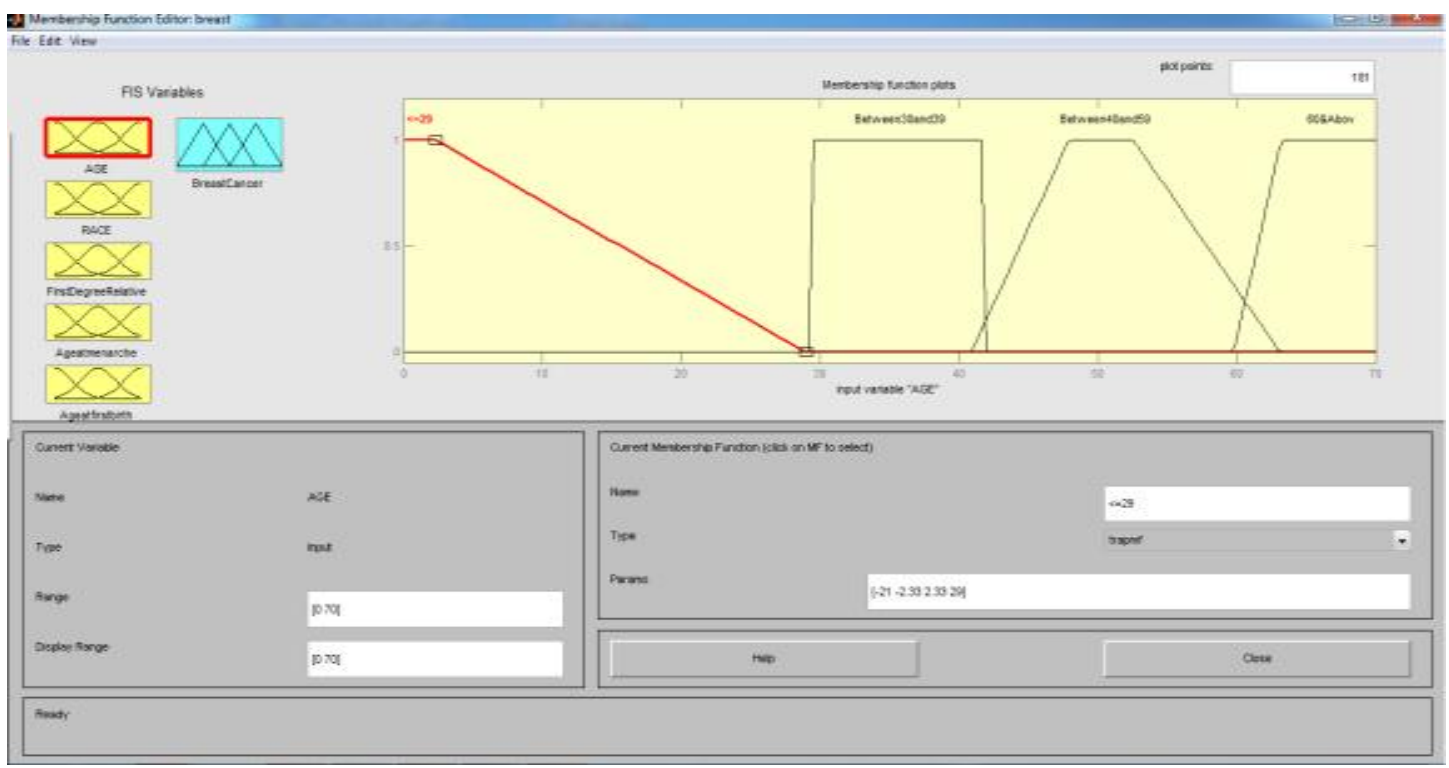

Fig-5: Membership Functions for Age

Race input variable has four fuzzy sets "Low, Medium, High and Very High" with individual probabilities .

\begin{tabular}{|l|c|c|}
\hline \multicolumn{3}{|c|}{ Race } \\
\hline Risk Factors & Fuzzy Set & Breast cancer Risk \\
\hline Mixed/Others & Low & $3 \%$ \\
\hline Black & Medium & $7 \%$ \\
\hline Hispanic & High & $11 \%$ \\
\hline White & Very High & $72 \%$ \\
\hline
\end{tabular}

Table 5:Fuzzy Sets Of Race

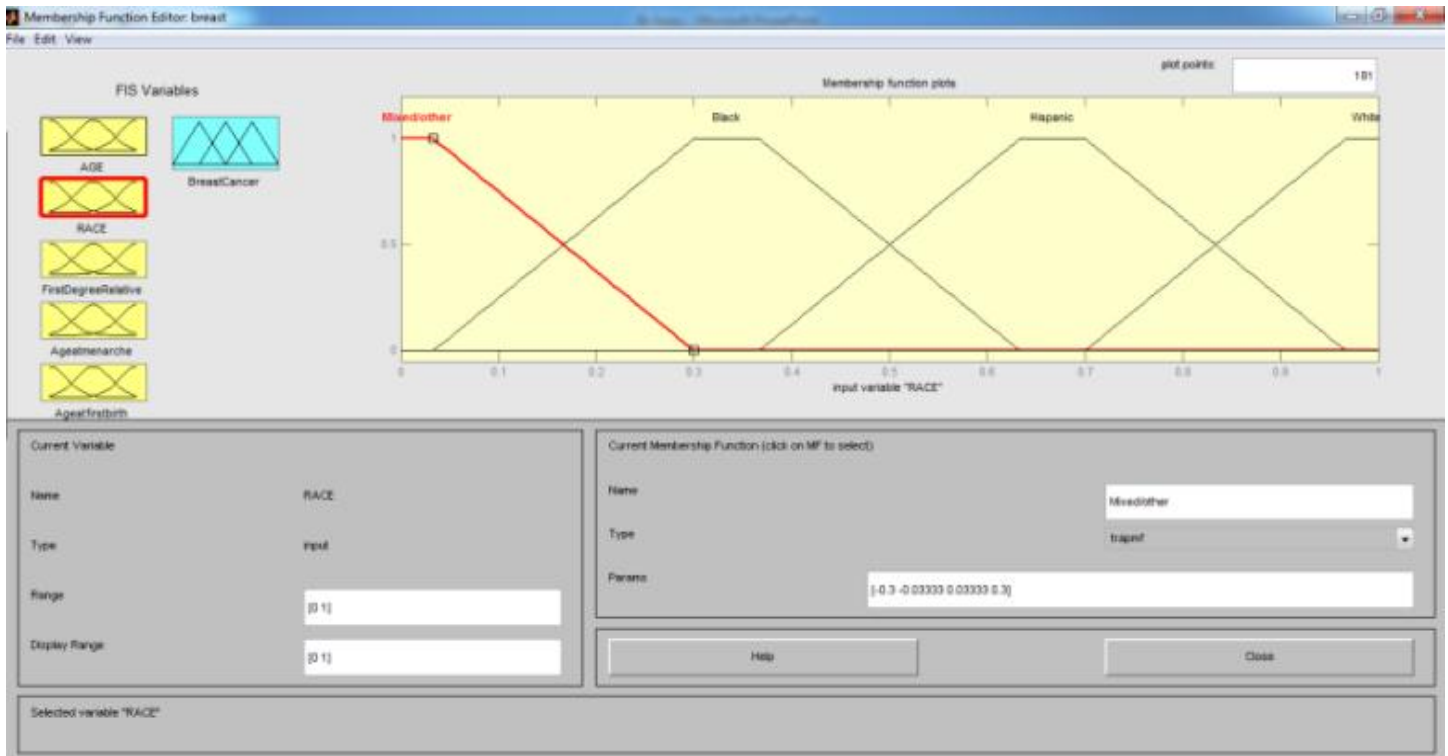

Fig- 6: Membership Functions for Race

First degree relative with breast cancer input variable has three fuzzy sets "Low, Medium and High " with individual probabilities

\begin{tabular}{|l|c|c|}
\hline \multicolumn{3}{|c|}{ First degree relative with breast cancer } \\
\hline Risk Factors & Fuzzy Set & Breast cancer Risk \\
\hline 0 & Low & $5 \%$ \\
\hline 1 & Medium & $20 \%$ \\
\hline$>=2$ & High & $40 \%$ \\
\hline
\end{tabular}

Table 6:Fuzzy Sets Of First Degree Relative with breast cancer 


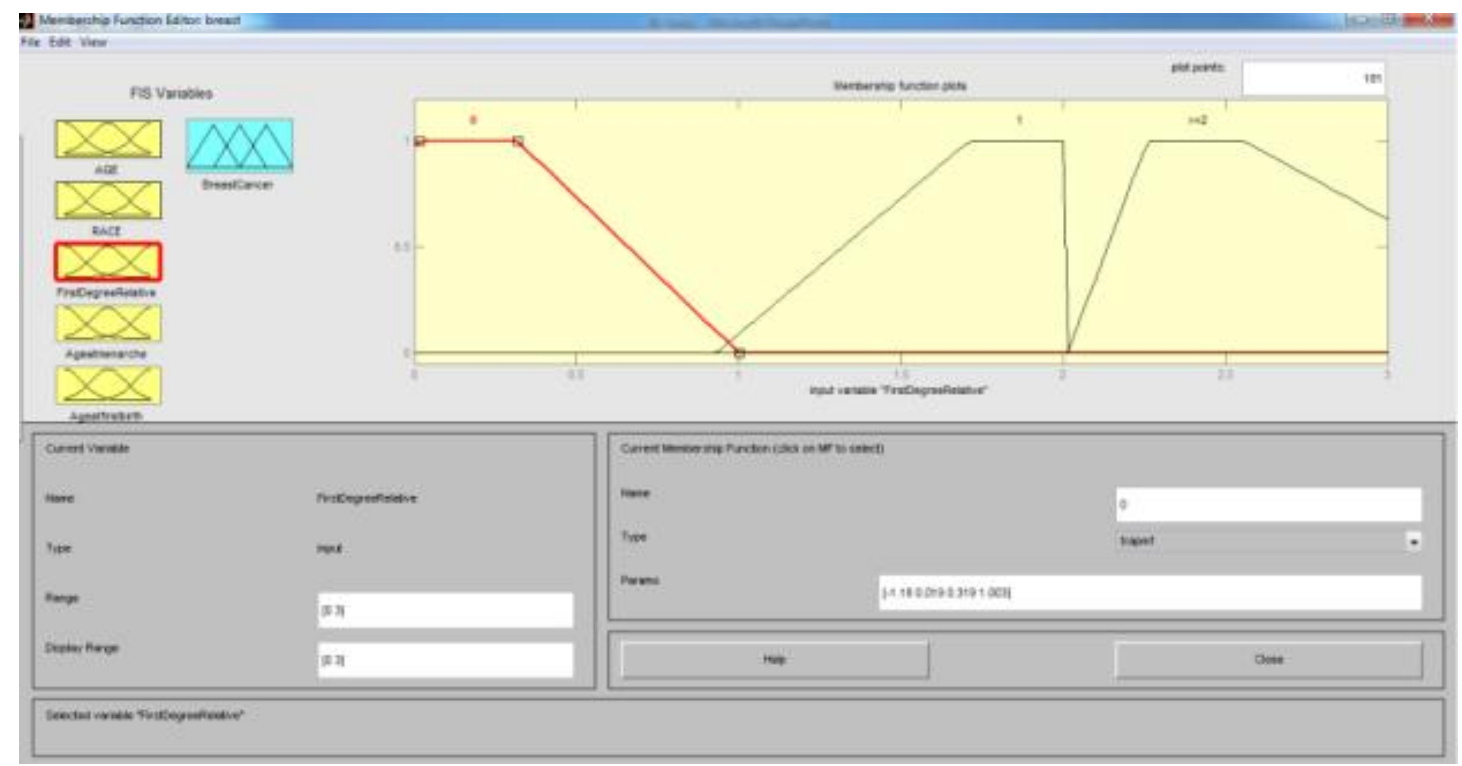

Fig-7 :Membership Functions for First degree relative with breast cancer

Age at menarche input variable has two fuzzy sets "Low, and very High " with individual probabilities .

\begin{tabular}{|l|c|c|}
\hline \multicolumn{3}{|c|}{ Age at menarche } \\
\hline Risk Factors & Fuzzy Set & Breast cancer Risk \\
\hline $12-13$ & low & $12 \%$ \\
\hline$<12$ or $\geq 15$ & Very High & $44 \%$ \\
\hline
\end{tabular}

Table7:Fuzzy Sets Of Age at Menarche

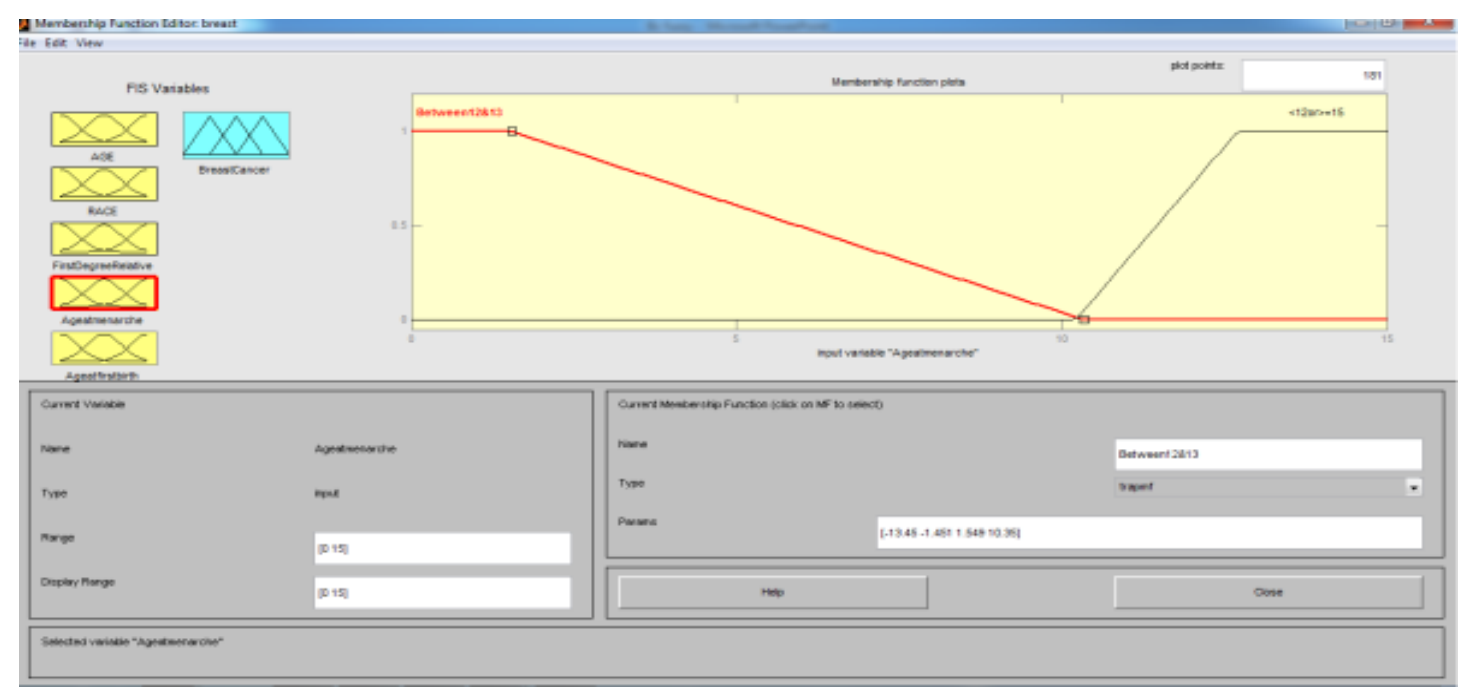

Fig- 8 :Membership Functions for Age at Menarche

Age at First Birth input variable has three fuzzy sets "Low, Medium and High " with individual probabilities

\begin{tabular}{|l|c|c|}
\hline \multicolumn{3}{|c|}{ Age at first birth } \\
\hline Risk Factors & Fuzzy Set & Breast cancer Risk \\
\hline$<20$ & Low & $17 \%$ \\
\hline $20-29$ & Medium & $31 \%$ \\
\hline$\geq 30$ or None & High & $49 \%$ \\
\hline
\end{tabular}

Table8:Fuzzy Sets Of Age at First Birth 


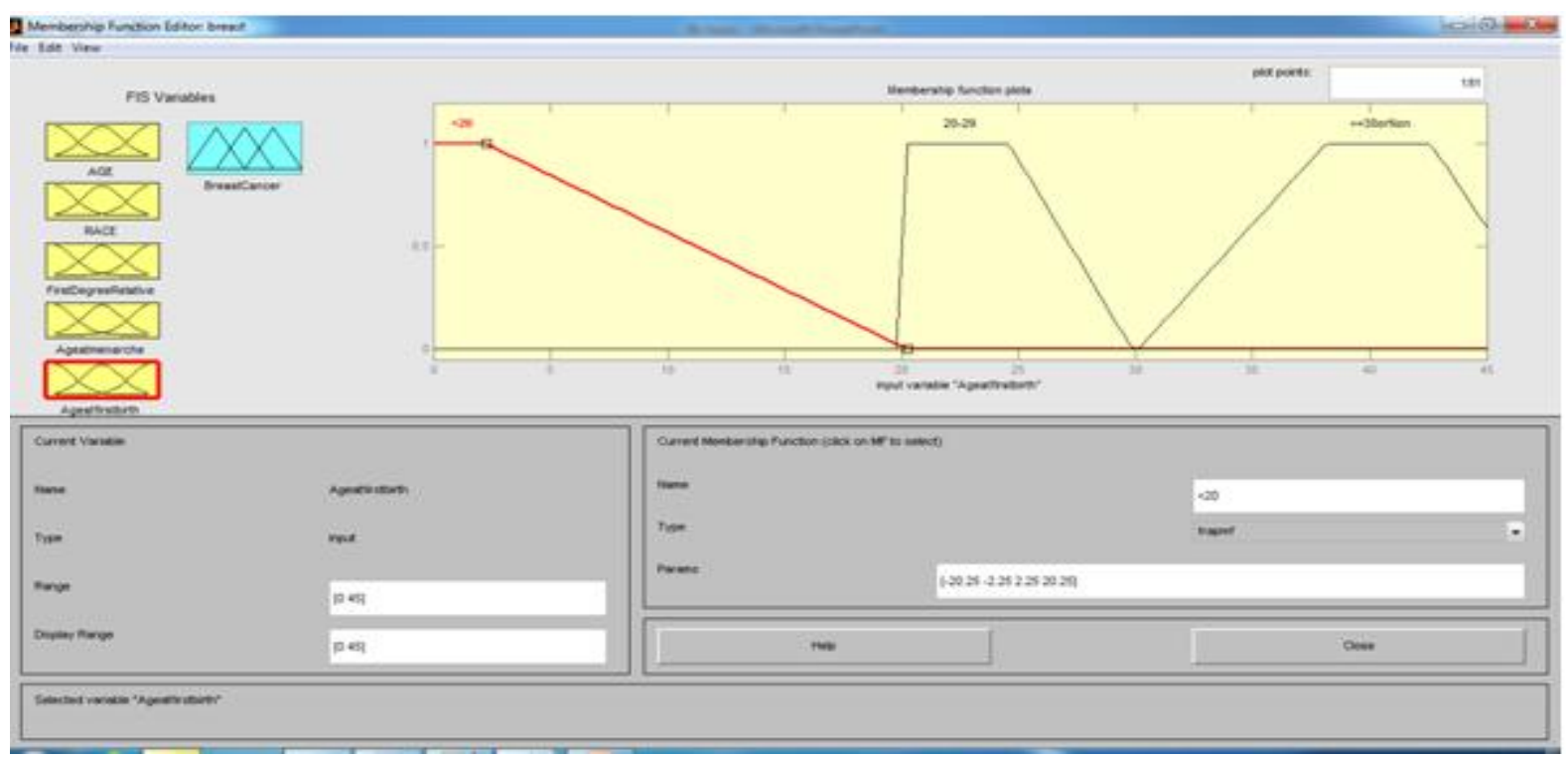

Fig-9 :Membership Functions for Age at First Birth

The "goal" of the system is to identify risk status of breast cancer. The output variable is a value from 0 to 4 ; representing Low Risk status, Medium Risk status High Risk status and very High Risk status.

\begin{tabular}{|c|c|c|}
\hline \multicolumn{3}{|l|}{ Output } \\
\hline \multirow{5}{*}{ Risk Status } & Range & Fuzzy Set \\
\hline & $0-1$ & Low \\
\hline & $1-2$ & Medium \\
\hline & $1-3$ & High \\
\hline & $2-4$ & Very High \\
\hline
\end{tabular}

Table 9 FUZZY Sets Of Output Variable Risk Status

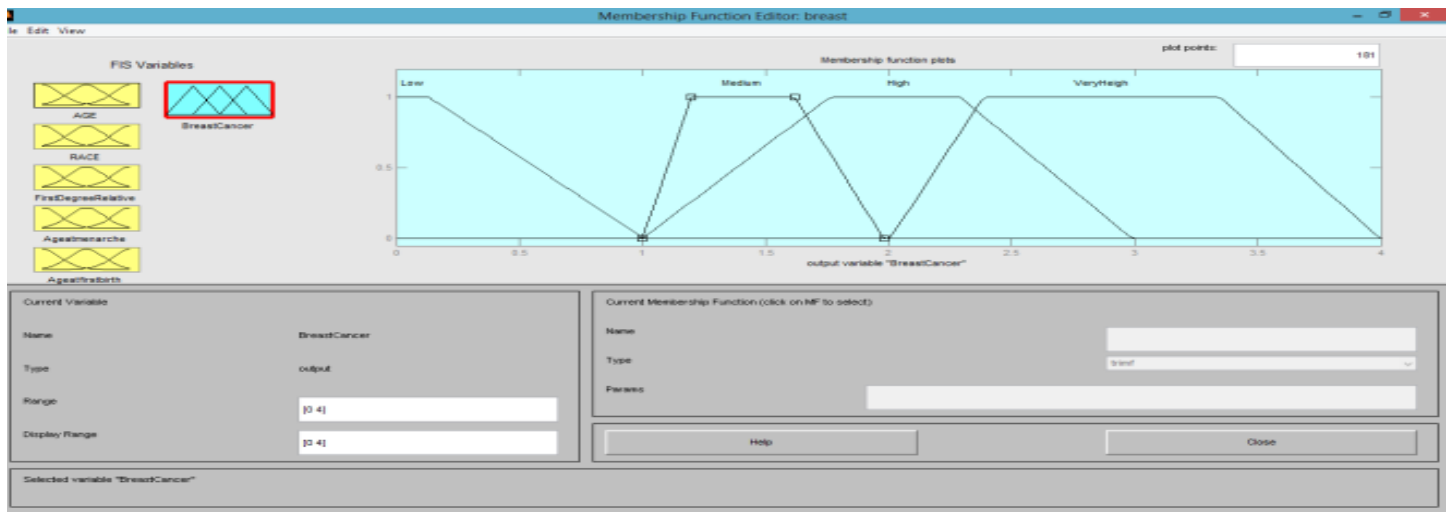

Fig-10 :Membership Functions for Risk Status

In this system, inference engine also performs probabilistic reasoning so called belief networks or bayesian Networks. Bayesian network gets probabilities about individual factor from probability tables that stored in the knowledge base and calculate the probability of breast cancer. In this system posterior probability that is breast cancer probability depends on five factors that consider prior probability and hard to compute manually. Therefore we use BayesiaLab for belief network .It shows in Figure 12 


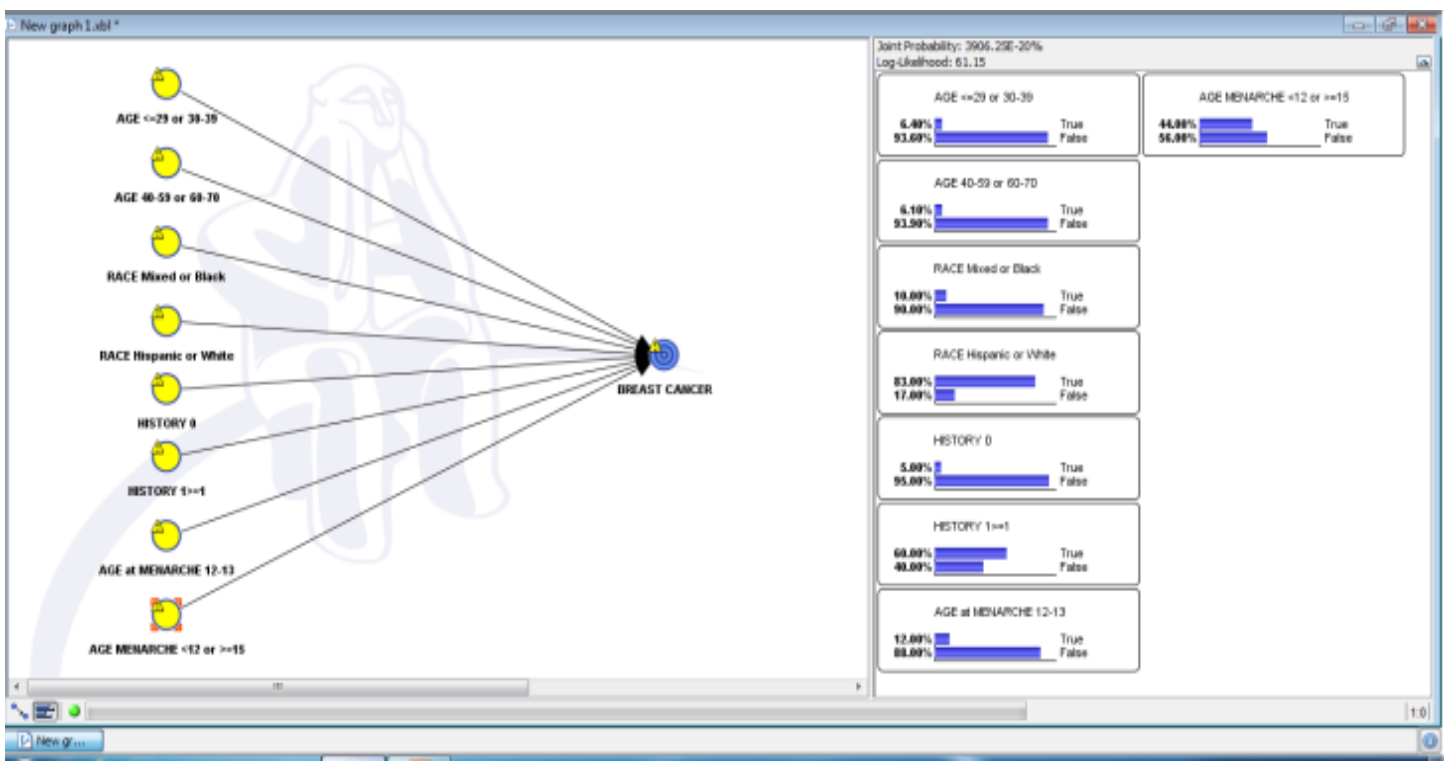

Fig-12 :Bayesian Network for Risk Status

\section{System testing and discussion}

System has been tested by experts and rules are defined by knowledge engineer . Some of the rules are shown in Table 9 and Figure.13.

1. $\quad$ IF $(($ age $\leq 29$ or $30 \leq$ age $\leq 39)$ and (Race $=$ Mixed $)$ and (History $=0)$ and $(12 \leq$ Age at menarche $\leq$ 13) and (Age at first birth $<20$ or $20 \leq$ Age at first birth $\leq 29)$ ) THEN the certainty factor is LOW

2. $\quad$ IF $(($ age $\leq 29$ or $30 \leq$ age $\leq 39)$ and $($ Race $=$ Mixed $)$ and (History $=0)$ and $(12 \leq$ Age at menarche $\leq$ 13) and (Age at first birth $>30$ or Non)) THEN the certainty factor is LOW

3. $\quad$ IF ((age $\leq 29$ or $30 \leq$ age $\leq 39)$ and (Race $=$ Mixed) and (History $=0)$ and (Age at menarche $<12$ or $\geq$ 15 ) and (Age at first birth $<20$ or $20 \leq$ Age at first birth $\leq 29)$ ) THEN the certainty factor isLOW

4. $\quad$ IF ((age $\leq 29$ or $30 \leq$ age $\leq 39)$ and (Race $=$ Mixed) and (History $=0)$ and (Age at menarche $<12$ or $\geq$ 15) and (Age at first birth $>30$ or Non)) THEN the certainty factor is LOW

5. $\quad$ IF $(($ age $\leq 29$ or $30 \leq$ age $\leq 39)$ and (Race $=$ Mixed) and (History $\geq 1)$ and $(12 \leq$ Age at menarche $\leq$ 13) and (Age at first birth $<20$ or $20 \leq$ Age at first birth $\leq 29)$ ) THEN the certainty factor isMEDIUM

6. $\quad$ IF $(($ age $\leq 29$ or $30 \leq$ age $\leq 39)$ and (Race $=$ Mixed $)$ and (History $\geq 1)$ and $(12 \leq$ Age at menarche $\leq$ 13) and (Age at first birth $>30$ or Non)) THEN the certainty factor isHIGH

7. IF ( age $\leq 29$ or $30 \leq$ age $\leq 39)$ and (Race $=$ Mixed) and (History $\geq 1)$ and (Age at menarche $<12$ or $\geq$ 15 ) and (Age at first birth $<20$ or $20 \leq$ Age at first birth $\leq 29)$ ) THEN the certainty factor isMEDIUM

8. $\quad$ IF ((age $\leq 29$ or $30 \leq$ age $\leq 39)$ and (Race $=$ Mixed) and (History $\geq 1)$ and (Age at menarche $<12$ or $\geq$ 15) and (Age at first birth $>30$ or Non)) THEN the certainty factor is HIGH

9. IF $(($ age $\leq 29$ or $30 \leq$ age $\leq 39)$ and (Race $=$ Black $)$ and $($ History $=0)$ and $(12 \leq$ Age at menarche $\leq 13)$ and (Age at first birth $<20$ or $20 \leq$ Age at first birth $\leq 29)$ ) THEN the certainty factor is LOW

10. $\quad$ IF $(($ age $\leq 29$ or $30 \leq$ age $\leq 39)$ and (Race $=$ Black) and (History $=0)$ and $(12 \leq$ Age at menarche $\leq$ 13) and (Age at first birth $>30$ or Non)) THEN the certainty factor is LOW

11. IF ( (age $\leq 29$ or $30 \leq$ age $\leq 39)$ and (Race $=$ Black $)$ and (History $=0)$ and (Age at menarche $<12$ or $\geq$ $15)$ and (Age at first birth $<20$ or $20 \leq$ Age at first birth $\leq 29)$ ) THEN the certainty factor is LOW

12. IF ((age $\leq 29$ or $30 \leq$ age $\leq 39)$ and (Race $=$ Black) and (History $=0)$ and (Age at menarche $<12$ or $\geq$ 15) and (Age at first birth $>30$ or Non)) THEN the certainty factor is LOW

13. IF $(($ age $\leq 29$ or $30 \leq$ age $\leq 39)$ and (Race $=$ Black) and (History $\geq 1)$ and $(12 \leq$ Age at menarche $\leq 13)$ and (Age at first birth $<20$ or $20 \leq$ Age at first birth $\leq 29)$ ) THEN the certainty factor is MEDIUM

14. IF ( (age $\leq 29$ or $30 \leq$ age $\leq 39)$ and (Race $=$ Black) and (History $\geq 1)$ and $(12 \leq$ Age at menarche $\leq 13)$ and (Age at first birth $>30$ or Non)) THEN the certainty factor is HIGH

15. IF ( age $\leq 29$ or $30 \leq$ age $\leq 39)$ and (Race $=$ Black) and (History $\geq 1)$ and $(12$ Age at menarche $<12$ or $\geq 15$ ) and (Age at first birth $<20$ or $20 \leq$ Age at first birth $\leq 29$ )) THEN the certainty factor isMEDIUM

Table 9:Rule Base Of the System 
Breast Cancer Monitoring and Tracking System using Soft Computing and Expert System....

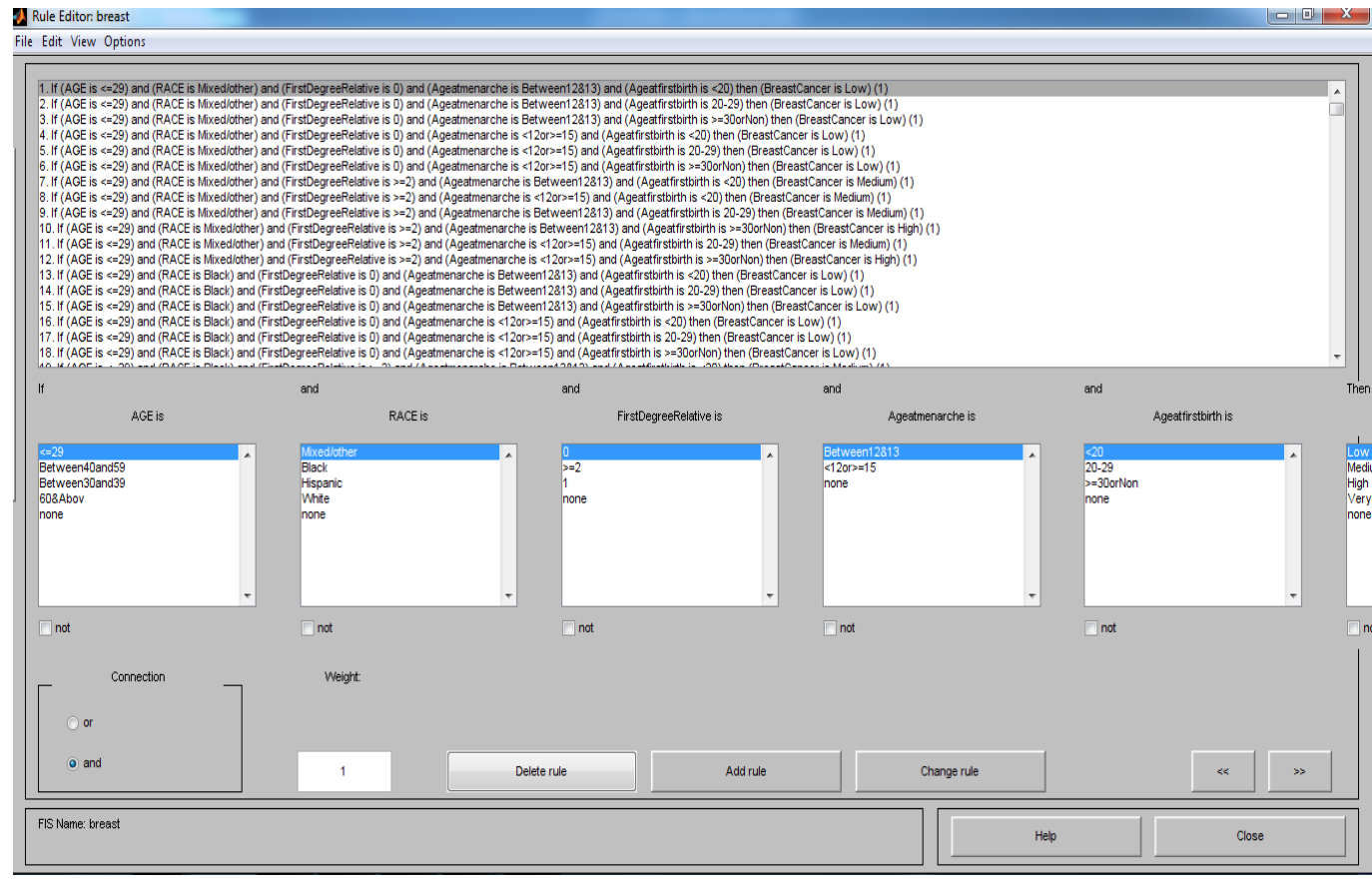

Fig-13:Rule Base Of the System

Figure 14- 17 shown surface viewer of some fields as follow

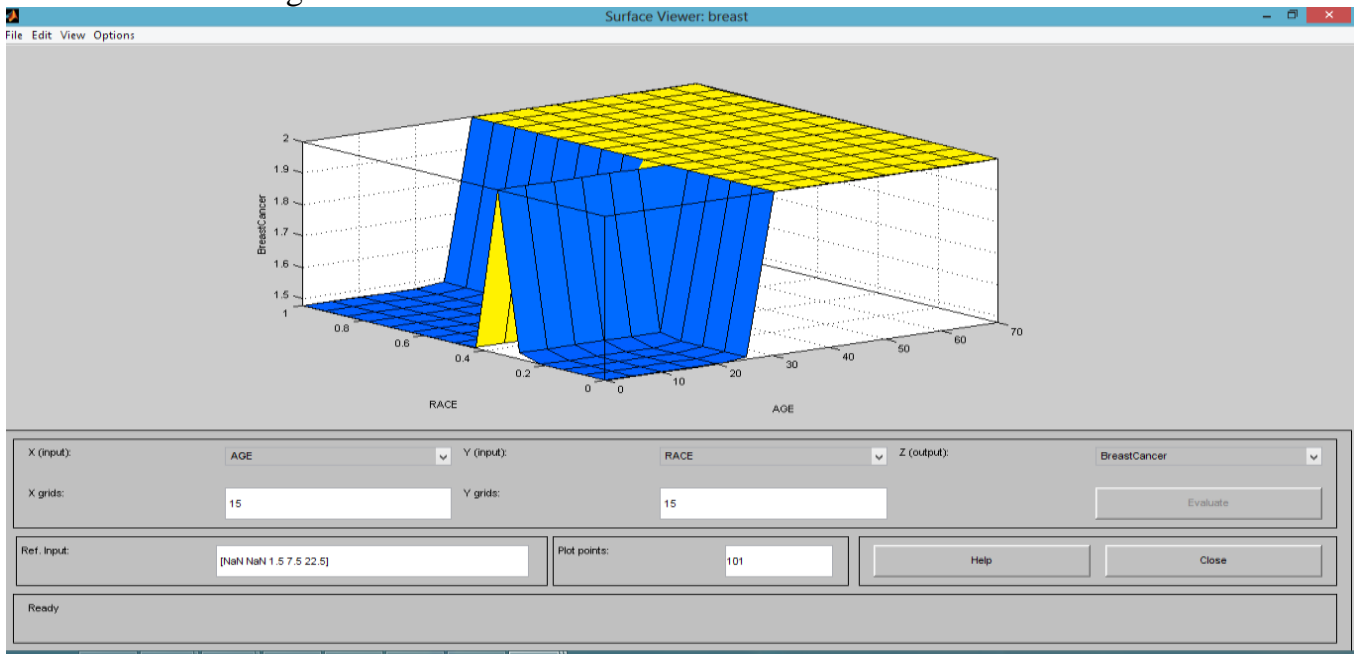

Fig- 14. Surface Viewer of Age and Race

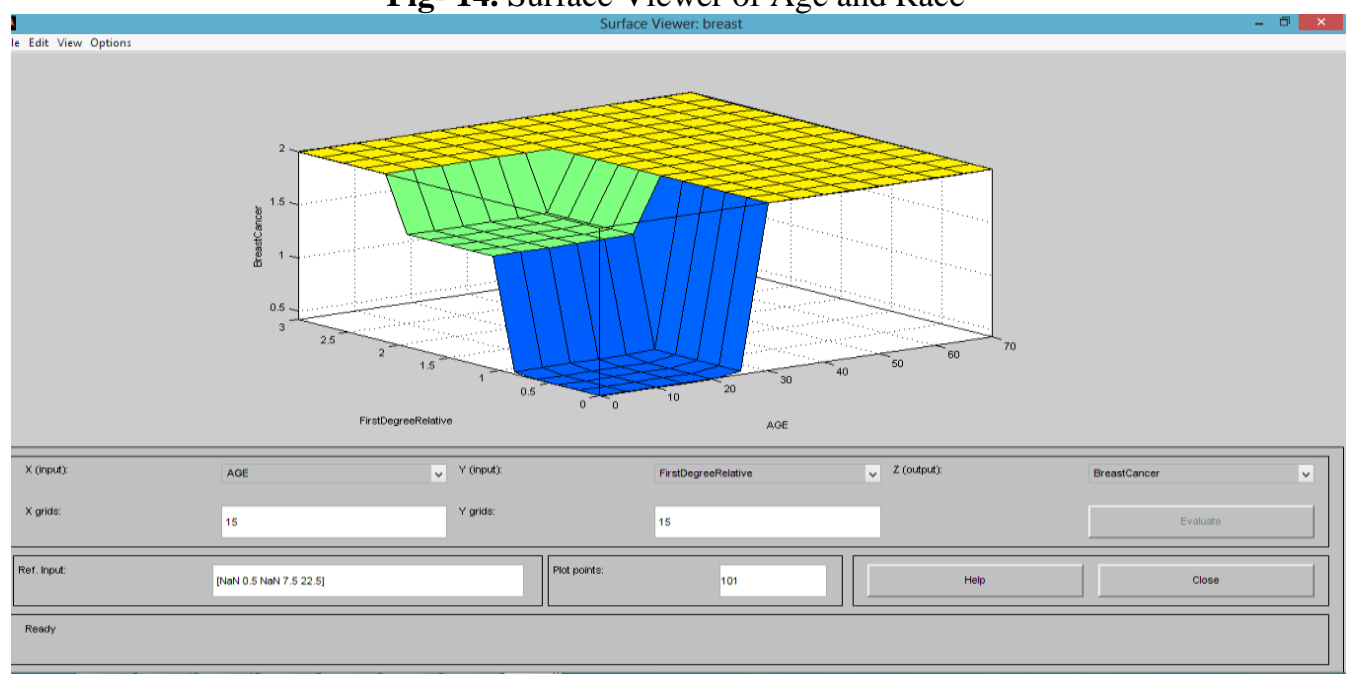

Fig-15. Surface Viewer of Age and First Degree Relative 
Breast Cancer Monitoring and Tracking System using Soft Computing and Expert System....

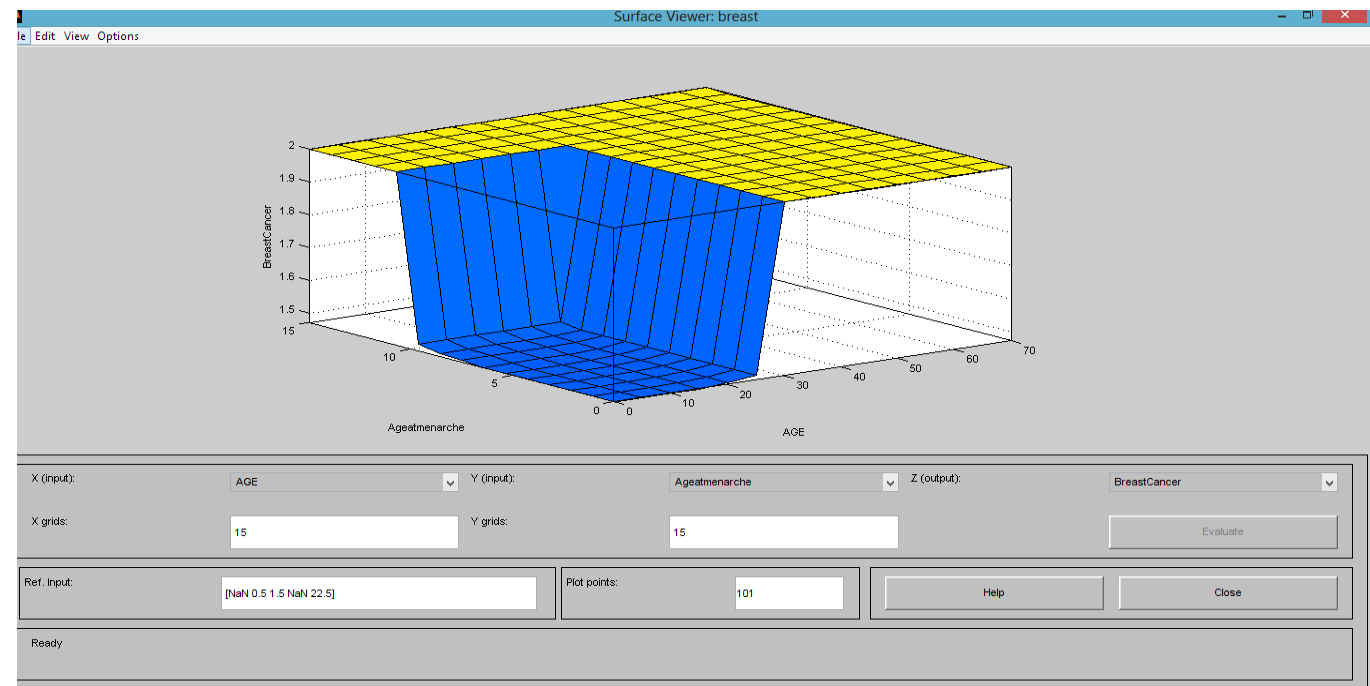

Fig-16. Surface Viewer of Age and Age at Menarche

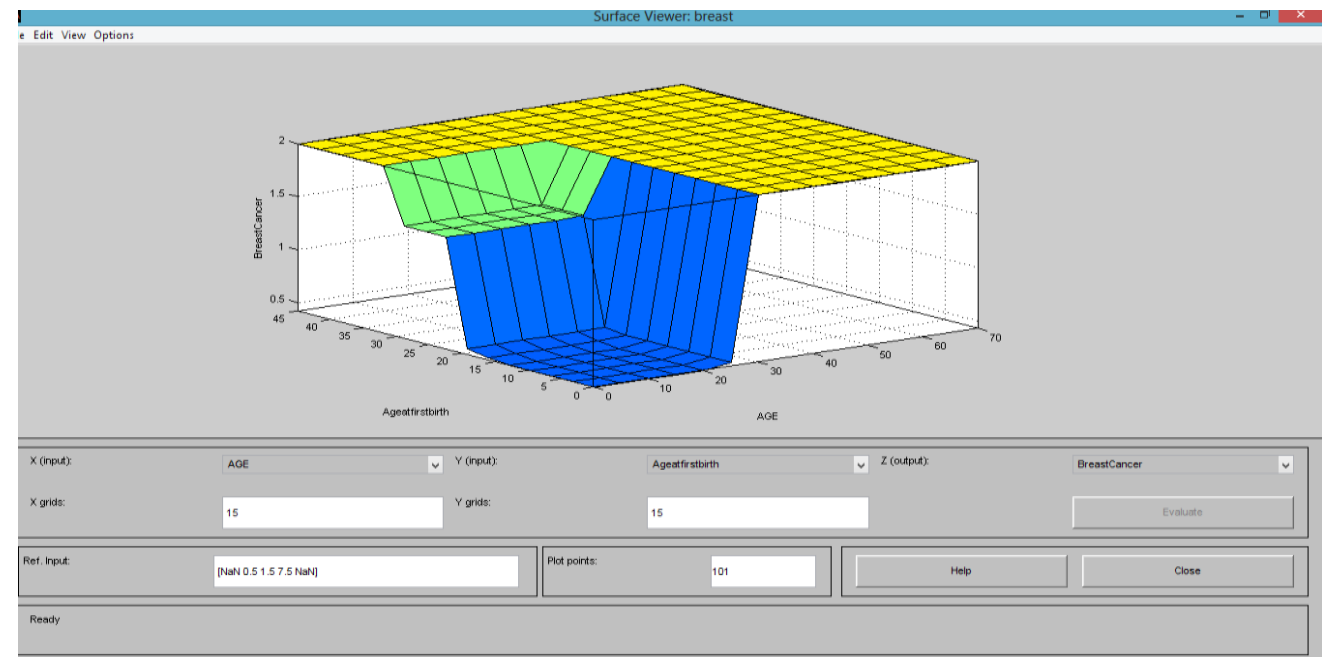

Figure 17. Surface Viewer of Age and Age at First Birth

After design of an Expert system, system has already implemented as it shown in the figure 18

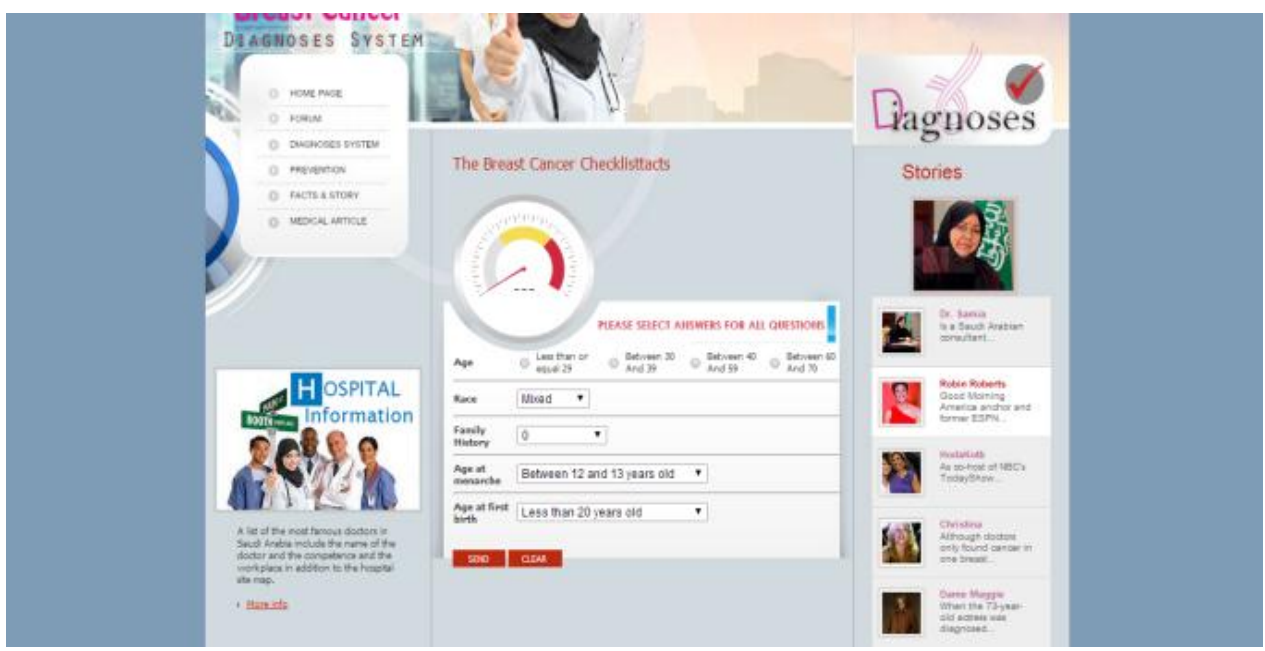

Figure 18. Breast Cancer System 


\section{Conclusion}

This paper describes design of expert system with soft computing techniques for identification of breast cancer risk status, which can be used by specialized doctors and patient for cancer treatment. The system design is based on membership functions, input variables, output variables, rule base and probabilistic reasoning. This research also shows fuzzy set by using MatLab and belief network by using BayesiaLab .This System has been tested by expert doctors. It is well said that "Health is Wealth" and this system helps patient in monitoring and diagnosis of breast cancer at home.

\section{Acknowledgements}

We acknowledge Dr.GhadderAbdeen in Aldamamhospital and Dr. KhaledAbulkhair Associate Consultant, Oncology in IMC Jeddah for their effort in this research.

\section{References}

[1]. Freddie Bray, P. M. (2004). The changing global patterns of female breast cancer incidence and mortality. BioMedCentral , 229239.

[2]. Carol DeSantis, M. ,. (2011). Breast Cancer Facts \& Figures . American Cancer Societ .

[3]. risk factors for breast cancer. (2014, $01 \quad 31)$ Retrieved from http://www.cancer.org/cancer/breastcancer/detailedguide/breast-cancer-risk-factors.

[4]. HussainSaleem\&et. al., (2010), “Traceability Management Framework for Patient Data in Healthcare Environment", In Proc. IEEE Intl. Conf. on Computer Science \& Information Technology, Chengdu, China, pp.264-8

[5]. Masood, A. (2011). MEDICAL EXPERT SYSTEM Theory, Implementation and Application: Knowledge Discovery from Medical Data Using a Bayesian Network and Fuzzy Logic . LAP LAMBERT. 